\title{
Three Offspring with Cri-du-Chat Syndrome from Phenotypically Normal Parents
}

\author{
Dilek U. Alkaya $^{a}$ Birsen Karaman $^{\mathrm{b}}$ Beyhan Tüysüz ${ }^{\mathrm{a}}$ \\ ${ }^{a}$ Department of Pediatric Genetics, Cerrahpasa Medical School, Istanbul University, Istanbul, Turkey; ${ }^{\text {b Department }}$ \\ of Medical Genetics, Medical School, Istanbul University, Istanbul, Turkey
}

\section{Established Facts}

- Cri-du-chat syndrome is a common chromosomal disorder caused by deletion of chromosome 5p.

- Most of the cases occur de novo. The recurrence risk is negligible in de novo deletions.

\section{Novel Insights}

- We detected a deletion of chromosome $5 \mathrm{p}$ due to an unbalanced translocation between $5 \mathrm{p} 13.3$ and 19q13.4 in 3 siblings with cri-du-chat syndrome phenotype. Parental karyotypes and FISH analysis were normal in peripheral blood and skin fibroblasts, which indicated gonadal mosaicism.

- FISH and microarray analysis of the father's sperm showed the same chromosome abnormality as in his children in a mosaic pattern.

- This is the first study that provides molecular evidence of gonadal mosaicism in cri-du-chat syndrome.

\section{Keywords}

Cri-du-chat syndrome $\cdot$ Gonadal mosaicism $\cdot 5 p$ deletion

\begin{abstract}
Cri-du-chat syndrome is characterized by facial dysmorphism, intellectual disability, and multiple congenital anomalies. Most cases occur de novo. Here, we report 3 siblings with cridu-chat syndrome born to healthy parents. The proband was admitted to our clinic at the age of 6.5 years due to severe intellectual disability, facial dysmorphism, and heart defect. His karyotype showed a deletion of chromosome $5 \mathrm{p}$. Microarray analysis revealed a 29-Mb deletion in chromosome $5 \mathrm{p}$ and a 4.7-Mb duplication in chromosome 19q. FISH analysis indicat-
\end{abstract}

ed an unbalanced translocation between 5p13.3 and 19q13.4. During follow-up, the second and the third child of the family were born with the same chromosome abnormality. Parental peripheral blood and skin fibroblast karyotypes as well as the FISH results using chromosome $5 p$ - and $19 q$-specific subtelomeric probes were normal. FISH analysis of the father's sperm detected a $5 p$ deletion in $12.8 \%$ of 200 cells, and microarray analysis confirmed the same unbalanced chromosome abnormality in a mosaic pattern. Uncultured peripheral blood and buccal smear of the father were also studied by FISH to exclude low-level mosaicism and in vitro culture effect. This is the first study that provides molecular evidence of paternal gonadal mosaicism of an unbalanced translocation detected in 3 siblings with cri-du-chat syndrome.

\section{KARGER}

(c) 2020 S. Karger AG, Basel

karger@karger.com

www.karger.com/msy
Beyhan Tüysüz

Department of Pediatric Genetics

Cerrahpasa Medical School, Istanbul University

Istanbul 34098 (Turkey)

beyhan@istanbul.edu.tr 
Cri-du-chat syndrome (CdCS) is a common chromosomal disorder which was first described by Lejeune in 1963 and is caused by terminal or interstitial deletion of the short arm of chromosome 5 [Lejeune et al., 1963]. The characteristic features of the syndrome are high-pitched voice mimicking a cat cry at birth, low birth weight, microcephaly, growth delay, severe neuromotor retardation, and facial dysmorphism including hypertelorism, broad nasal bridge, epicanthal folds, downslanting palpebral fissures, low-set ears, and retromicrognathia [Mainardi et al., 2001]. Cardiac, neurological, genitourinary, gastrointestinal, and ocular abnormalities have been reported in this syndrome [Mainardi et al., 2006]. The incidence of CdCS is between $1 / 15,000$ and $1 / 50,000$ live births [Niebuhr, 1978a; Higurashi et al., 1990]. The prevalence is $1.5 / 1,000$ in patients with intellectual disability and $1 / 305$ in patients who seek genetic counseling and are analyzed cytogenetically [Niebuhr, 1978a; Duarte et al., 2004].

The phenotypic features of the syndrome vary among patients with different breakpoints and deletion sizes. Deletion sizes range from $560 \mathrm{~kb}$ to $40 \mathrm{Mb}$ [Simmons et al., 1995; $\mathrm{Gu}$ et al., 2013]. The critical regions of the syndrome are 5 p15.2 and 5 p15.3. Deletion of 5 p15.3 is responsible for the typical cat-like cry and speech delay, whereas deletion of 5 p 15.2 is responsible for dysmorphic features, microcephaly, and intellectual disability [Overhauser et al., 1994; Mainardi et al., 2001; Wu et al., 2005; Zhang et al., 2005; Elmakky et al., 2014]. Larger deletions are associated with more severe neurological impairment [Mainardi et al., 2001].

Most of the cases occur de novo. Parental translocations are responsible for $10-15 \%$ of the patients [Mainardi et al., 2006]. The recurrence risk is insignificant in de novo deletions; however, it is possible that one of the parents may have gonadal mosaicism.

Here, we describe 3 siblings with severe clinical findings of CdCS born to phenotypically normal parents as an example of gonadal mosaicism in this syndrome.

\section{Case Reports}

Patient 1 was a 6.5 -year-old boy born to consanguineous healthy parents. His father was 24 and his mother was 19 years of age when he was born. He had no remarkable family history. His birth weight, height, and head circumference were within normal ranges. On admission, his weight, height, and head circumference were below the 3rd percentile. Physical examination disclosed a round face, downslanting palpebral fissures, hypertelorism, epicanthal folds, broad nasal bridge, downturned corners of the mouth, retromicrognathia, low-set ears (Fig. 1a), high-arched pal- ate, operated preauricular skin tags, widely spaced hypoplastic nipples, bilateral transverse lines, hypospadias, operated cryptorchidism, inguinal hernia, and bilateral talipes cavus (Table 1). He also underwent an operation for congenital cardiac defect. On cranial MRI, brain stem atrophy and hypoxic changes were detected. On eye examination, no vision could be assessed, and bilateral optic discs were temporally pale. Neuromotor development was significantly delayed. At 4 years of age, unsupported sitting was just achieved, and at 18 years of age, he was not able to walk, and speech consisted of 2-3 words.

In the subsequent pregnancy of the mother, fetal ultrasonography revealed dilated intestinal loops and stomach, a single umbilical vessel, cerebral ventriculomegaly, cerebellar hypoplasia, and oligohydramnios. Amniocentesis was performed due to multiple anomalies. Although genetic counseling was given to the family, the pregnancy was not terminated. The affected fetus (patient 2) was born at the 36th week of gestation. She had hypertelorism, micrognathia, low-set ears, short neck, and intestinal atresia. At the second postnatal day, she was operated for intestinal atresia and died 8 days after the operation (Table 1).

The parents underwent 2 in vitro fertilization (IVF) attempts, which failed due to the finding of unbalanced chromosome abnormalities determined by preimplantation diagnostic tests. After these IVF attempts, the third child was born by spontaneous pregnancy.

Patient 3 had the characteristic facial findings of CdCS and a high-pitched cry at birth. He had microcephaly, hypertelorism, epicanthal folds, downslanting palpebral fissures, broad nasal bridge, retromicrognathia, preauricular tag, inguinal hernia, micropenis, and developmental delay (Fig. 1b; Table 1). His echocardiography was normal. At 12 months of age, he had convulsions, so antiepileptic treatment was started. Corpus callosum agenesis was found in cranial ultrasonography. He achieved head control at 18 months of age, and on the last assessment at the age of 3 years, he could not sit without support.

\section{Cytogenetic and Molecular Cytogenetic Studies}

Chromosome analysis was performed on phytohemagglutininstimulated peripheral blood lymphocytes, amnion fluid, and skin fibroblasts. Because of the suspicion of mosaicism, at least 100 metaphases were analyzed by GTG-banding.

FISH analysis was carried out with probes specific for chromosome 5, chromosome 19 subtelomeres, as well as with wholechromosome painting probes (D5S23 probe, Aquarius Cat cry probe; Vysis $5 p$ and $5 q$ subtelomere probes; and Vysis $19 p$ and $19 q$ subtelomere probes). A total of 500 cells were evaluated by FISH on metaphase or interphase nuclei to exclude low-level mosaicism.

Oligonucleotide microarray was performed using Agilent SurePrint G3 CGH+SNP Microarray Kit (4x180K). The signals were captured by a Roche NimbleGen MS 200 Microarray Scanner. Microarray data were analyzed using Feature Extraction software and Agilent CytoGenomics v4.0.3.12 software. Genomic positions were based on the UCSC February 2009 human reference sequence (hg19) (NCBI build 37 reference sequence assembly). Unfiltered microarray data analysis was performed to detect mosaicism.
98

Mol Syndromol 2020;11:97-103 DOI: $10.1159 / 000506892$
Alkaya/Karaman/Tüysüz 
Table 1. Clinical features of the 3 siblings and percentages of these features in reported patients

\begin{tabular}{|c|c|c|c|c|}
\hline & Patient 1 & Patient 2 & Patient 3 & $\begin{array}{l}\text { Mainardi et al., } 2006 \\
(n=220)\end{array}$ \\
\hline Sex & M & $\mathrm{F}$ & M & - \\
\hline Age at first examination & 6.5 years & 1 st day & 1st day & - \\
\hline Age at last examination & 19 years & Deceased at 10th day & 3 years & - \\
\hline Height, $\mathrm{cm}$ & 154 (<3rd percentile) & NA & 88 (3rd-10th percentile) & - \\
\hline Typical cry at birth & + & + & + & $95.9 \%$ \\
\hline Hypotonia & + & + & + & $72.2 \%$ \\
\hline \multicolumn{5}{|l|}{ Facial dysmorphism } \\
\hline Hypertelorism & + & + & + & $81.4 \%$ \\
\hline Epicanthal fold & + & + & + & $90.2 \%$ \\
\hline Preauricular skin tag & + & - & + & $9 \%$ \\
\hline Heart defect & ASD, VSD, PDA & $\mathrm{PFO}$ & - & $35.8 \%$ \\
\hline Urogenital anomaly & Hypospadias, cryptorchidism & - & Micropenis & $12.6 \%$ \\
\hline Ocular problems & Pale optic disc; no vision & NA & NA & $56.6 \%$ \\
\hline Gastrointestinal anomaly & - & Intestinal atresia & - & $21.4 \%$ \\
\hline Epilepsy & - & - & + & $15.7 \%$ \\
\hline Intellectual disability & Severe & $?$ & Severe & Moderate to severe \\
\hline Cranial imaging & $\begin{array}{l}\text { Brain stem atrophy and } \\
\text { hypoxic changes }\end{array}$ & $\begin{array}{l}\text { Prenatal ultrasound: } \\
\text { ventriculomegaly, cerebellar } \\
\text { hypoplasia }\end{array}$ & $\begin{array}{l}\text { Corpus callosum } \\
\text { agenesis }\end{array}$ & $29.8 \%$ \\
\hline Other & $\begin{array}{l}\text { Bilateral talipes cavus; } \\
\text { inguinal hernia }\end{array}$ & $\begin{array}{l}\text { Prenatal ultrasound: dilated } \\
\text { intestinal loops and stomach; } \\
\text { single umbilical vessel }\end{array}$ & Inguinal hernia & $\begin{array}{l}\text { Dental malocclusion, pes } \\
\text { planus/valgus/varus/equinus; } \\
\text { clubfoot; scoliosis; inguinal } \\
\text { hernia; allergies }\end{array}$ \\
\hline
\end{tabular}

F, female; M, male; NA, not available; ASD, atrial septal defect; VSD, ventricular septal defect; PDA, patent ductus arteriosus; PFO, patent foramen ovale.

\section{Results}

Chromosome analysis of the 3 siblings by GTG-banding revealed a deletion of chromosome $5 p$ (Fig. 1c). The microarray analyses of patients 1 and 3 showed a $4.7-\mathrm{Mb}$ duplication of $19 \mathrm{q} 13.42 \mathrm{q} 13.43$ in addition to the $28.9-\mathrm{Mb}$ deletion of $5 \mathrm{p} 15.33 \mathrm{p} 13.3$, suggesting an unbalanced translocation between 5p13.3 and 19q13.4 (Fig. 1g, h). FISH analyses confirmed the unbalanced translocation (Fig. 1d-f). The final karyotype was determined as 46,XY,der(5)t(5;19)(p.13.3;q13.42).arr[GRCh37] 5p15.3 3 p 13.3(22149_29014014)×1,19q13.42q13.43 (54361209_59095418) $\times 3$. No other pathological copy number variations were identified by microarray. The regions of homozygosity could not be analyzed due to technical limitations of the oligonucleotide microarray.

The detection of the same chromosome abnormality in 3 offspring of healthy parents suggested parental gonadal mosaicism.

Peripheral blood and skin fibroblast karyotypes as well as the FISH results using chromosome 5p- and 19q-specific subtelomeric probes were normal in both parents. FISH analysis of the father's sperm with a chromosome $5 p$ subtelomeric probe detected a $5 p$ deletion in $12.8 \%$ of the 200 counted cells, which confirmed paternal mosaicism. To investigate a possible low-level somatic mosaicism, uncultured peripheral blood and buccal smear FISH analysis, skin fibroblast and peripheral blood interphase FISH analysis, and skin fibroblast and sperm microarray analy- 

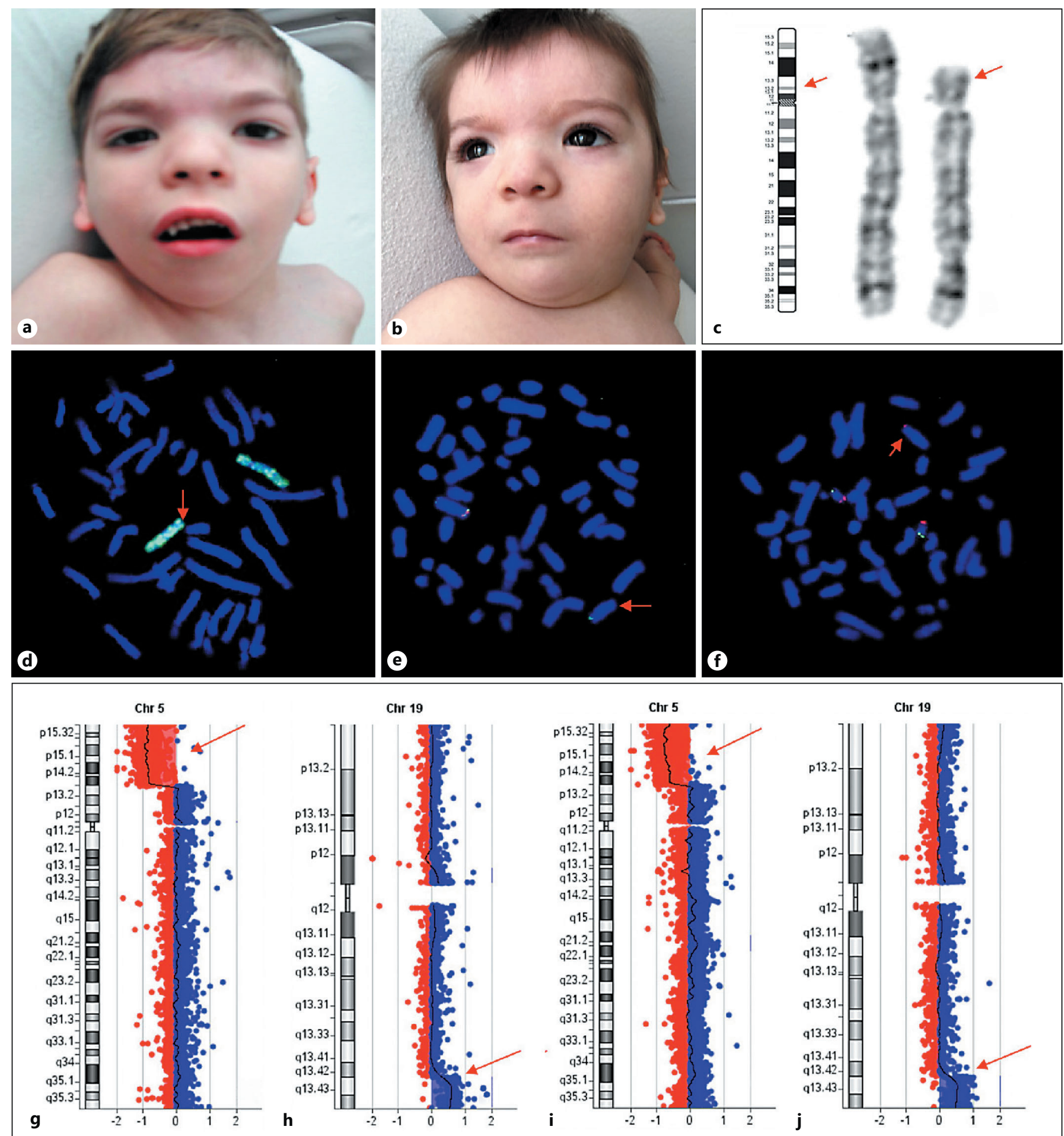

(For legend see next page.) 
sis of the father were performed. Only microarray analysis of the father's sperm showed the same unbalanced chromosome abnormality as in the children in a mosaic pattern (Fig. 1I, 1J) suggesting gonadal mosaicism.

\section{Discussion}

Here, we report 3 siblings diagnosed with CdCS, who had a 28.9-Mb deletion in chromosome 5p15.33p13.3 and a 4.7-Mb duplication in chromosome 19q13.42q13.43 due to an unbalanced translocation between 5 p13.3 and 19 q13.4 as an example of paternal gonadal mosaicism.

In our study, all patients had the typical facial characteristics of CdCS, and the 2 patients who survived had severe neurocognitive impairment. The clinical features of our patients are summarized in Table 1.

Phenotypic features of CdCS vary depending on deletion size and breakpoints. The critical regions which are responsible for the characteristic cry and the remaining features are well demonstrated in several studies and related to deletion of $5 \mathrm{p} 15.3$ and $5 \mathrm{p} 15.2$, respectively [Overhauser et al., 1994; Mainardi et al., 2001; Wu et al., 2005; Zhang et al., 2005; Elmakky et al., 2014]. Chromosome $5 \mathrm{p}$ deletions not including the critical regions do not represent the characteristics of CdCS as cat-like cry or speech delay. Short terminal 5p15.3 deletions exhibit a mild phenotype [Kushnick et al., 1984; Overhauser et al., 1986; Baccichetti et al., 1988; Rossi et al., 2005]. Large deletions and unbalanced translocations in CdCS are associated with severe neurological impairment and higher frequency of congenital malformations [Wilkins et al., 1983; Mainardi et al., 2001]. Patients with large deletions, similar to our patients, were reported to have severe intellectual disability, severe speech delay, behavioral problems, and musculoskeletal involvement [de Carvalho et al., 2008; Santo et al., 2016]. Santo at al. [2016] described a 38-year-old patient with similar chromosome 5 p deletion size who had severe speech delay, difficulty in walking, facial asymmetry, early graying

Fig. 1. a Patient 1 at the age of 6.5 years, presenting with microcephaly, hypertelorism, epicanthal folds, high nasal bridge, downslanting palpebral fissures, downturned corners of mouth, retrognathia, and low-set ears. b Patient 3 at the age of 8 months, showing microcephaly, downslanting palpebral fissures, broad nasal bridge, hypertelorism, epicanthal folds, and retromicrognathia. c The peripheral blood karyotype of patient 1 showed $5 p$ deletion after GTG-banding. d-f Peripheral blood metaphase FISH analyses in patients $1(\mathbf{d})$ and $3(\mathbf{e}, \mathbf{f})$. d Whole chromosome painting hair, hypertonia, scoliosis, and self-mutilation. Additionally, preauricular tags have been reported in a 17-month-old boy diagnosed with Goldenhar syndrome because of hemifacial microsomia and with a large distal $5 \mathrm{p}$ deletion similar to our patients [Wang and Khan, 2010].

The clinical features of our patients were correlated with CdCS, but in microarray analysis, we also found a $4.7-\mathrm{Mb}$ duplication in chromosome 19q13.42q13.43. Terminal 19q13.3 duplications have been reported to be associated with neuromotor retardation, speech delay, epilepsy, short stature, abnormal ears, and short neck [Bhat et al., 2000; Resta et al., 2013; Carvalheira et al., 2014]. Two siblings who had a $4.3-\mathrm{Mb}$ duplication in $19 \mathrm{q} 13.42 \mathrm{q} 13.43$ (similar to our patients) with learning difficulties, short stature, dysmorphic facial features including hypertelorism, low set ears, and prominent chin, have been described, and it is suggested that these patients have clinical features similar to $19 \mathrm{q}$ terminal duplication reported previously [Balasubramanian et al., 2016]. Although some dysmorphic features (hypertelorism, lowset ears) overlap between $5 p$ deletion and $19 q$ duplication, our patients did not have other features of $19 \mathrm{q} d u-$ plication like prominent chin. Therefore, we concluded that the $19 \mathrm{q}$ duplication did not contribute to the phenotype of our patients.

Gonadal and/or somatic mosaicism are rare reasons for the familial recurrence of genetic disorders. Almost all de novo chromosomal anomalies are sporadic, and the recurrence risk is estimated to be low. Gonadal mosaicism occurs due to a mutation in a dividing germ cell or in an early somatic cell before separation of germinal cells and is present in both germinal and somatic cells [Zlotogora, 1998]. The proportion of the chromosomal abnormality and the type of the tissues involved are main factors that affect the phenotype. Mosaicism has been described in genetic diseases for a long time. Mosaicism in trisomy 21 was reported for the first time in 1962 [Blank et al., 1962]. To date, several studies observed gonadal mosaicism in chromosomal diseases and microdeletion/and $5 \mathrm{q}$ subtelomere probes confirmed the deletion of chromosome $5 p$ (red arrow). $\mathbf{f}$ Probes specific to chromosome 19p and 19q subtelomeres showed the duplication of chromosome 19q (red arrow). $\mathbf{g - j}$ Microarray analyses of peripheral blood DNA of patient $3(\mathbf{g}, \mathbf{h})$ and sperm DNA of the father analyzed with mosaic filter $(\mathbf{i}, \mathbf{j})$. Note the deletion in 5p15.33p13.3 and duplication of 19q13.42q13.43 (red arrows). 
duplication syndromes such as Williams, DiGeorge, Prader Willi, and Angelman syndromes [Kara-Mostefa et al., 1999; Kokkonen and Leisti, 2000; Engel et al., 2001; Fernández-Novoa et al., 2001; Sandrin-Garcia et al., 2002; Tabolacci et al., 2005; Rump et al., 2008]. Many of the cases with mosaicism are undetected because of lowlevel mosaicism or tissue-specific mosaicism. Microarray analysis has recently been reported to be superior to other tests [Cheung et al., 2007]. Testing the DNA extracted from whole blood, no need for cell culture, and analysis of different cell types and cell stages are advantages of microarray-based techniques [Biesecker and Spinner, 2013].

In our study, clinically unaffected parents had normal peripheral blood and skin fibroblast karyotypes, thus suggesting gonadal mosaicism.

Somatic mosaicism (5\% mosaicism in blood lymphocytes and 3\% mosaicism in skin fibroblasts) in 5p14 deletion was reported in a mother of a fetus and a child with the same chromosome abnormality [Niebuhr, 1978b]. Gonadal mosaicism of $5 p$ deletion was also described in a case of recurrence of del(5)(p.15.2) identified at prenatal diagnosis [Hajianpour et al., 1991]. In our study, the sperm analysis of the father by FISH and microarray methods detected a 5p15.33p13.3 deletion and $19 \mathrm{q} 13.42 \mathrm{q} 13.43$ duplication due to an unbalanced translocation between chromosome 5p13.1 and 19q13.4 in a mosaic pattern which had previously been found in his affected children.

Mosaicism for structural chromosomal rearrangements is extremely rare, detected in $0.002 / 1,000$ patients with reproductive failure [Kovaleva and Cotter, 2016]. Asymptomatic carriers of non-centromeric rearrangements with affected children were evaluated in a study, and among them 33 of 42 were found to be mosaic for an unbalanced rearrangement including 16 ring chromosomes, 8 duplications, 4 unbalanced translocations, and 5 other rearrangements [Kovaleva and Cotter, 2016]. It has also been reported that the prevalence of asymptomatic carriers of an unbalanced rearrangement is more common in females due to male-specific selection against abnormal cells [Kovaleva and Cotter, 2016]. Gonadal mosaicism in unbalanced chromosome abnormalities is mostly due to postzygotic mutations, but it can also originate during meiosis in trisomic zygotes by 2 parallel trisomic rescue events. SNP array allows determining the origin of unbalanced rearrangements. Robberecht et al. [2012] reported that among 9 unbalanced chromosome mutations, 2 occurred during meiosis. Since oligonucleotide microarray was performed in our study, it was not possible to decide whether the mosaicism originated from meiotic or postzygotic error.

In conclusion, this is the first report that provides molecular evidence for gonadal mosaicism of an unbalanced translocation in CdCS. Genetic counseling in gonadal mosaicism is difficult and depends on the degree of mosaicism in gonadal cells. Genetic counselors should consider the possibility of gonadal mosaicism in CdCS patients, and fetal karyotype and FISH analysis should be offered in the following pregnancy to the family.

\section{Acknowledgement}

The authors would like to thank the patient's family for participating in this study.

\section{Statement of Ethics}

All procedures followed were in accordance with the ethical standards of the responsible committee on human experimentation (institutional and national) and with the Helsinki Declaration of 1975 , as revised in 2000. Informed consent was obtained from all patients for being included in the study. This study was approved by the Istanbul University Cerrahpasa Ethics Committee (03.01.2018-2606).

\section{Disclosure Statement}

The authors have no conflicts of interest to declare.

\section{Funding Sources}

The author(s) received no financial support for the research, authorship, and/or publication of this article.

\section{Author Contributions}

All authors gave final approval of the work and agree to be accountable for it, ensuring that questions related to the accuracy or integrity of any part of the work were appropriately investigated and resolved. B.T. and B.K. made substantial contributions to the conception and design of the work; acquisition, analysis, and interpretation of data; and critical revision. D.U.A. provided contributions to the acquisition, analysis, and interpretation of data and drafted the work. 


\section{References}

Baccichetti C, Lenzini E, Artifoni L, Caufin D, Marangoni P: Terminal deletion of the short arm of chromosome 5. Clin Genet 34:219223 (1988).

- Balasubramanian M, Cartwright A, Smith K, Arundel P, Bishop NJ: Copy number variants in association with type 1 collagenopathy: atypical osteogenesis imperfecta. Am J Med Genet A 170A:476-481 (2016).

-Bhat M, Morrison P, Getty A, McManus D, Tubman R, Nevin N: First clinical case of small de novo duplication of $19 \mathrm{q}(13.3-13.4)$ confirmed by FISH. Am J Med Genet 91:201-203 (2000).

Biesecker LG, Spinner NB: A genomic view of mosaicism and human disease. Nat Rev Genet 14:307-320 (2013).

Blank CE, Gemmell E, Casey MD, Lord M: Mosaicism in a mother with a mongol child. $\mathrm{Br}$ Med J 2:378-380 (1962).

- Carvalheira G, Oliveira MM, Takeno S, de Lima FT, MeloniVA,MelaragnoMI:19q13.33 $\rightarrow$ qter trisomy in a girl with intellectual impairment and seizures. Meta Gene 2:799-806 (2014).

-Cheung SW, Shaw CA, Scott DA, Patel A, Sahoo T, et al: Microarray-based CGH detects chromosomal mosaicism not revealed by conventional cytogenetics. Am J Med Genet A 143A:1679-1686 (2007).

de Carvalho AFL, da Silva Bellucco FT, Kulikowski LD, Toralles MBP, Melaragno MI: Partial $5 \mathrm{p}$ monosomy or trisomy in 11 patients from a family with a $\mathrm{t}(5 ; 15)(\mathrm{p} 13.3 ; \mathrm{p} 12)$ translocation. Hum Genet 124:387-392 (2008).

Duarte AC, Cunha E, Roth J, Ferriera F, Garcias G, Martino-Roth MG: Cytogenetics of genetic counseling patients in Pelotas, Rio Grande do Sul, Brazil. Genet Mol Res 3:303-308 (2004).

-Elmakky A, Carli D, Lugli L, Torelli P, Guidi B, et al: A three-generation family with terminal microdeletion involving 5p15.33-32 due to a whole-arm 5;15 chromosomal translocation with a steady phenotype of atypical cri du chat syndrome. Eur J Med Genet 57:145-150 (2014).

Engel U, Bohlander SK, Bink K, Hinney B, Laccone F, Bartels I: Pseudo dicentric chromosome $(5 ; 21)$ : a rare example of maternal germline mosaicism: case report. Hum Reprod 16: 63-66 (2001).

-Fernández-Novoa MC, Vargas MT, Vizmanos JL, Garnacho C, Martinez JJ, et al: Prader-Willi syndrome large deletion on two brothers. Is this the exception that confirm the rule? (in Spanish). Rev Neurol 32:935-938 (2001).

- Gu H, Jiang JH, Li JY, Zhang YN, Dong XS, et al: A familial cri-du-chat $/ 5 p$ deletion syndrome resulted from rare maternal complex chromosomal rearrangements (CCRs) and/or possible chromosome 5p chromothripsis. PLoS One 8:e76985 (2013).
Hajianpour A, Murer-Orlando M, Docherty Z: Germ line mosaicism for chromosome 5 "cridu chat" deletion? Am J Hum Genet 49 (Suppl):217, abstract 1176 (1991).

Higurashi M, Oda M, Iijima K, Iijima S, Takeshita $\mathrm{T}$, et al: Livebirth prevalence and follow-up of malformation syndromes in 27,472 newborns. Brain Dev 12:770-773 (1990).

-Kara-Mostefa A, Raoul O, Lyonnet S, Amiel J, Munnich A, et al: Recurrent Williams-Beuren syndrome in a sibship suggestive of maternal germ-line mosaicism. Am J Hum Genet 64: 1475-1478 (1999).

Kokkonen H, Leisti J: An unexpected recurrence of Angelman syndrome suggestive of maternal germ-line mosaicism of del(15)(q11q13) in a Finnish family. Hum Genet 107:83-85 (2000).

Kovaleva NV, Cotter PD: Somatic/gonadal mosaicism for structural autosomal rearrangements: female predominance among carriers of gonadal mosaicism for unbalanced rearrangements. Mol Cytogenet 9:8 (2016).

Kushnick T, Rao KW, Lamb AN: Familial 5psyndrome. Clin Genet 26:472-476 (1984).

Lejeune J, Lafourcade J, Berger R, Vialatte J, Boeswillwald $\mathrm{M}$, et al: 3 cases of partial deletion of the short arm of a 5 chromosome (in French). C R Hebd Seances Acad Sci 257: 3098-3102 (1963).

-Mainardi PC, Perfumo C, Cali A, Coucourde G, Pastore G, et al: Clinical and molecular characterisation of 80 patients with $5 p$ deletion: genotype-phenotype correlation. J Med Genet 38:151-158 (2001).

Mainardi PC, Pastore G, Castronovo C, Godi M, Guala A, et al: The natural history of cri du chat syndrome. A report from the Italian register. Eur J Med Genet 49:363-383 (2006).

Niebuhr E: The cri du chat syndrome. Epidemiology, cytogenetics, and clinical features. Hum Genet 44:227-275 (1978a).

Niebuhr E: Cytologic observations in 35 individuals with a 5p- karyotype. Hum Genet 42:143156 (1978b).

Overhauser J, Golbus MS, Schonberg SA, Wasmuth JJ: Molecular analysis of an unbalanced deletion of the short arm of chromosome 5 that produces no phenotype. Am J Hum Genet 39:1-10 (1986).

- Overhauser J, Huang X, Gersh M, Wilson W, McMahon J, et al: Molecular and phenotypic mapping of the short arm of chromosome 5: sublocalization of the critical region for the cri-du-chat syndrome. Hum Mol Genet 3: 247-252 (1994).

Resta N, De Cosmo L, Susca FC, Capodiferro D, Nardone AM, et al: De novo unbalanced translocation leading to monosomy 9p24.3p24.1 and trisomy 19q13.42q13.43 characterized by microarray-based compara- tive genomic hybridization in a child with partial cortical dysplasia and craniofacial dysmorphisms without trigonocephaly. Am J Med Genet A 161A:632-636 (2013).

-Robberecht C, Voet T, Utine GE, Schinzel A, de Leeuw N, et al: Meiotic errors followed by two parallel postzygotic trisomy rescue events are a frequent cause of constitutional segmental mosaicism. Mol Cytogenet 5:19 (2012).

Rossi E, de Gregori M, Grazia Patricelli M, Pramparo T, Argentiero, $\mathrm{L}$, et al: $8.5 \mathrm{Mb}$ deletion at distal $5 p$ in a male ascertained for azoospermia. Am J Med Genet A 133A:189-192 (2005).

Rump P, Dijkhuizen T, Sikkema-Raddatz B, Lemmink HH, Vos YJ, et al: Drayer's syndrome of mental retardation, microcephaly, short stature and absent phalanges is caused by a recurrent deletion of chromosome 15(q26.2 $\rightarrow$ qter). Clin Genet 74:455-462 (2008).

-Sandrin-Garcia P, Macedo C, Martelli LR, Ramos ES, Guion-Almeida ML, et al: Recurrent $22 \mathrm{q} 11.2$ deletion in a sibship suggestive of parental germline mosaicism in velocardiofacial syndrome. Clin Genet 61:380-383 (2002).

- Santo E, Damasceno L, Moreira LMA, Riegel M: Cri-du-chat syndrome: clinical profile and chromosomal microarray analysis in six patients. Biomed Res Int 2016:5467083 (2016).

- Simmons AD, Goodart SA, Gallardo TD, Overhauser J, Lovett M: Five novel genes from the cri-du-chat critical region isolated by direct selection. Hum Mol Genet 4:295-302 (1995).

Tabolacci E, Zollino M, Lecce R, Sangiorgi E, Gurrieri F, et al: Two brothers with $22 \mathrm{q} 13$ deletion syndrome and features suggestive of the Clark-Baraitser syndrome. Clin Dysmorphol 14:127-132 (2005).

Wang JC, Khan A: Large distal 5p deletion with hemifacial microsomia and absence of cri-duchat syndrome. Clin Dysmorphol 19:38-39 (2010).

Wilkins LE, Brown JA, Nance WE, Wolf B: Clinical heterogeneity in 80 home-reared children with cri du chat syndrome. J Pediatr 102:528533 (1983).

Wu Q, Niebuhr E, Yang H, Hansen L: Determination of the "critical region" for cat-like cry of cri-du-chat syndrome and analysis of candidate genes by quantitative PCR. Eur J Hum Genet 13:475-485 (2005).

Zhang X, Snijders A, Segraves R, Zhang X, Niebuhr A, et al: High-resolution mapping of genotype-phenotype relationships in cri du chat syndrome using array comparative genomic hybridization. Am J Hum Genet 76: 312-326 (2005).

Zlotogora J: Germ line mosaicism. Hum Genet 102:381-386 (1998).
Offspring with Cri-du-Chat Syndrome from Phenotypically Normal Parents
Mol Syndromol 2020;11:97-103 DOI: $10.1159 / 000506892$ 